\title{
The Effects of Oral Reading Practice on English Language Ability and Metacognition of Oral Reading among Japanese Senior High School Students
}

\author{
MIYASAKO, Nobuyoshi \\ Joint Graduate School, Hyogo University of Teacher Education
}

\section{INTRODUCTION}

It seems that reading aloud or oral reading has made a comeback in English language teaching in Japan. There are two main reasons for this. One is anecdotal evidence, mainly shown by English-speaking professionals in various fields, that reading aloud is helpful for the improvement of their English language proficiency.

The other is the development in cognitive psychology (Anderson, 1995; Williams \& Burden, 1997), especially in the studies on working memory (Baddeley, 1992, 1997, 1999; Baddeley, Gathercole \& Papagno, 1998; Gathercole \& Baddeley, 1993). It is suggested that the efficiency of working memory might be improved by strengthening subvocal rehearsal in the phonological loop through practices such as oral reading and shadowing, i.e., repeating someone's utterances almost simultaneously following them like their shadows while listening to them. Consequently, more efficient functioning of phonological loop may lead to better listening and reading comprehension.

Moreover, some traditional criticism against oral reading has been proved to be inadequate. The criticism includes: (a) learners who are overloaded in comprehending a text while reading aloud tend to do parrot-reading, i.e., oral reading without comprehension (Takanashi \& Takahashi, 1987); and (b) oral reading often hinders developing learners' reading speed or understanding the gist of a text (Takayama, 1995). The first problem can be solved if learners read a text aloud after comprehending it. The second problem should not be emphasized because the reading speed of learners usually does not differ between silent and oral reading. The slow reading of learners is considered to be rooted in their excessive dependence on such reading strategies as sentence-level translation and dictionary use.

The main rationales assumed for reading aloud to improve learners' English language ability $^{1}$ are: (a) to provide learners with English exposure that helps to expand their vocabulary including fixed phrases; (b) to enhance the development of learners' grammar through consciousness raising; and (c) to improve the efficiency in the phonological processing of written information, or to form an appropriate acoustic image in the letter-recognizing process, which is expected to lead to better listening and reading comprehension (Miyasako, 2002).

The first point concerns how frequently learners need to encounter lexical items in order to acquire them. Although this frequency has been reported to vary from 5 to 16 according to researchers (Nation, 1990), it can be easily achieved in oral reading practice. 
Thus, in continuing oral reading of comprehensible passages, learners are supposed to acquire the unfamiliar lexical items in the passages.

Grammatical consciousness raising, which is grammar teaching aimed at explicit knowledge (Ellis, 1997), should take place spontaneously in oral reading for learners like Japanese senior high school students with explicit grammar teaching, which is another way of grammatical consciousness raising. These learners, who are highly conscious of grammar, tend to pay attention to some grammatical constructions in reading comprehensible passages aloud, if their cognitive load is not too heavy. In this case, the learners may be able to notice the gaps with their interlanguages, and this may lead to their restructuring, as has been shown by SLA researchers (Ellis, 1997; Schumidt, 2001; Skehan, 1998). Therefore, oral reading may enhance learners' grammar through consciousness raising.

The third point concerns the phonological loop of working memory. It was reported that college students improved their listening comprehension by practicing shadowing, which had a favorable effect on the efficiency of subvocal rehearsal in the phonological loop (Tamai, 2001). Kadota (2002) suggested a comparable effect of shadowing practice on reading comprehension because of the similarity in the cognitive process between listening and reading comprehension. Furthermore, Miyasako (2003) revealed the analogous function of subvocal rehearsal in the phonological loop between shadowing and oral reading. Thus, oral reading may possibly improve the efficiency of phonological processing.

Empirically, the efficiency of phonological coding, measured as the speed of oral reading, was improved by oral reading practice for senior high school students (Miyasako, 2002; Suzuki, 1998; Watanabe, 1990), which supports the above assumption concerning the phonological processing of words. Another finding on the efficiency of phonological coding was its significant correlation with reading comprehension for senior high school students (Miyasako \& Takatsuka, in press). Congruously, it was reported that the practice of reading aloud in class improved silent reading speed of senior high school students (Suzuki, 1998; Watanabe, 1990). Moreover, Kido (1993) revealed that oral reading practice improved the writing ability of senior high school students.

In order to investigate the effectiveness of oral reading practice in the improvement of English language ability, Miyasako (2002) conducted a three-month study examining the effects of 15- to 20-minute oral reading practice in 65-minute classes for senior high school students. In the study, the control group $(n=37)$ had regular English I classes and the experimental group $(\mathrm{n}=36)$ had condensed English I classes and oral reading practice. The results were: (a) the experimental group improved their oral reading speed and oral reading ability significantly more than the control group; (b) the experimental and control groups had no significant difference in the improvement of English language ability; and (c) the experimental group had a significantly more favorable change in the metacognition of oral reading, i.e., the perceptions on the practice and strategy-use in oral reading. 
Although the results (a) and (c) were valued as the effectiveness of oral reading practice, there remained a problem in the result (b) that both the experimental and control groups, which were matched in English language ability, similarly showed a significant improvement in English language ability. This result may be interpreted as indicating that oral reading practice had no effective role to play in the improvement of English language ability, but there is some possibility that oral reading practice was responsible for the improvement of English language ability for the experimental group for the following reasons. First, the experimental group had just about two-thirds as much time allotted for learning new materials as the control group during the experiment because the teaching of new materials was condensed to create time for oral reading practice of already covered materials. Second, the improvement of the control group may have been caused by the highly-demanding teacher for this group who gave more tests and assignments to the group than to the experimental group taught by another teacher, because of peer pressure irrelevant to this experiment. In short, these disadvantages of the experimental group may have been compensated by oral reading practice.

Thus, it is worth re-examining the possibility of oral reading practice having improved English language ability for the experimental group and who would have been the beneficiaries of oral reading practice. This time we sought to explore factors, among others, English language ability, oral reading ability and the amount of oral reading practice, which might have affected the improvement of English language ability for the experimental group. The improvement of English language ability was compared between higher and lower groups of these factors within the experimental group. Also investigated were the effects of these factors on the changes in the metacognition of oral reading for the experimental group.

\section{RESEARCH QUESTIONS}

The research questions of the present study were as follows:

(1) Who improved English language ability more greatly, senior high school students with higher or lower English language ability?

(2) Did oral reading ability and the amount of oral reading practice for senior high school students affect the improvement of their English language ability?

(3) Did English language ability, oral reading ability and the amount of oral reading practice for senior high school students affect the changes of their metacognition of oral reading?

\section{METHOD}

This section first reviews the participants of the experimental group, test materials and reading-aloud practice in Miyasako (2002), and next shows the analyses made in the re-examination. 


\subsection{Participants}

The participants of the experimental group in the three-month experiment (Miyasako, 2002) were 36 first-year students who had sporadically practiced reading aloud in class at a senior high school in Okayama.

\subsection{Test Materials}

Oral reading ability of the participants was analytically measured with reading-aloud passages used in the past STEP pre-second grade examinations before and after the experiment. The ability was evaluated by two Japanese EFL teachers ${ }^{2}$ based on four criteria, which were pronunciation, intonation, pause-making and delivery, its full marks being 20 with 5 points for each component (Appendix 1).

English language ability of the participants was gauged as the T-score of Bennese-Shinken-moshi ${ }^{3}$, a nationwide senior-high-school achievement test, administered in October and January. The metacognition of oral reading of the participants was surveyed with the 85-item questionnaire of 5-point Likert scale based on the questionnaires on reading strategies (Carrell, 1989; Watanabe, 1990). Out of these items, 4 factors and 51 items, which proved significant with factor-loading more than $|.50|$ by the principalcomponent factor analysis with Varimax rotation (Appendix 2), were dealt with in the analyses.

The amount of oral reading practice of the participants was measured based on the reading-aloud counts in their oral reading journals ${ }^{4}$, which included their feelings about the practice and reading speed (WPM) as well. The amount was counted as the frequency with which the participants read aloud the 150 - to 200 -word text of one section in the stages (4), (5) and (7) shown in section 3.3 below, whether in class or out of class.

\subsection{Oral Reading Practice}

Oral reading was practiced for 15 to 20 minutes in the 65-minute course of English I three times a week for three months, which made the total amount of practice in class about 450 minutes. The reading material consisted of the first five lessons of the course book, Spectrum English Course I (Shiozawa, 1998), which the students had already studied. The material was divided into twelve sections of 150 - to 200-word texts, each of which was allotted a day, with twelve days making a cycle. Oral reading out of class was practiced on a voluntary basis.

The basic procedure in class was devised based on Kunihiro $(1999,2000)$ as follows: (1) to listen to the tape $e^{5}$ once without looking at the text; (2) to listen to the tape once looking at the text; (3) to read the text silently once checking comprehension with the translation; (4) to read aloud each sentence of the text after the tape at least once; (5) to read the text aloud simultaneously with the tape at least once; (6) to optionally try shadowing; and (7) to read the text aloud at least twice. 
In steps (4), (5) and (7) the participants individually read the text aloud as frequently as possible in the periods. Steps (1) to (3) were omitted after one month, and instead the time allotted for steps (4) and (5) was increased. In the middle of the third month, the students preferred new material to read aloud, and that was fulfilled by using some other lessons of the course book.

This procedure was adopted because it was compatible with our above-shown assumption of oral reading practice on the enhancement of phonological processing of written information, which might consequently lead to the other assumed effects, i.e., the development of grammar and vocabulary (Section 1).

\subsection{Analysis}

The analyses for the re-examination were administered in the following manner. First, the participants were divided into upper, intermediate and lower groups based on their oral reading ability and English language ability as measured in the pre-tests and on their amount of oral reading practice in terms of the reading-aloud counts in their journals. The participants above 55 and below 45 as measured by the standardized scores, T-scores, in the pre-tests were respectively assigned to the upper and lower English-language-ability and oral-reading-ability groups. Similarly the upper and lower amount-of-oral-readingpractice (hereafter oral-reading-practice) groups had the participants with their T-scores above 55 and below $44^{6}$ respectively in the reading-aloud amount.

One reason for the adoption of T-scores 55 and 45 as the criterion for grouping the participants was that the normal distribution, which Shiken-moshi had with about 400,000 examinees, should provide $31 \%$ of the population for the score above 55 and below 45 respectively. Another was that the findings of this study might be applicable to other senior high school students all over Japan with the same range of English language ability.

Second, the effects of three-month oral reading practice on English language ability and the metacognition of oral reading were examined with independent one-way repeatedmeasures analyses of variance (ANOVAs) between the upper and lower English-language -ability, oral-reading-ability and oral-reading-practice groups. Three-way repeatedmeasures ANOVA, which would have been a more appropriate procedure, could not be performed because of the small number of the participants.

\section{RESULTS}

\subsection{Descriptive Statistics}

Table 1 shows the means of English language ability and oral reading ability for the participants in the pre-tests and the amount of oral reading practice for them in the reading-aloud counts. 


\subsection{Effects on English Language Ability}

\subsubsection{English Language Ability}

Table 2 shows the means of English language ability for the upper and lower English-language-ability groups. The lower group (pre $=42.121$, post $=47.071$ ) gained more points than the upper group (pre $=57.725$, post $=59.262$ ) in the mean of English language ability during the experiment. According to the 2 (English language ability) $\mathrm{x} 2$ (period) repeated-measures ANOVA, there were significant main effects of condition [F (1, $20)=114.340, p<.01]$ and period $[F(1,20)=16.412, p<.01]$. The interaction between the condition and period was also significant $[F(1,20)=4.541, p<.05]$. It seems that the lower English-language-ability group improved their English language ability significantly more than the upper English-language-ability group during the experiment.

Table 1. Means of English Language Ability and Oral Reading Ability in Pre-tests and Amount of Oral Reading Practice in Journal Record

\begin{tabular}{ccccccc}
\hline Group & $\mathrm{n}$ & \multicolumn{2}{c}{ Score } & & \multicolumn{2}{c}{ T-score } \\
\cline { 3 - 4 } \cline { 6 - 7 } & & Mean & SD & & Mean & SD \\
\hline English language & ability* & & & & \\
Upper & 8 & & & & 57.725 & 2.745 \\
Lower & 14 & & & & 42.121 & 2.940 \\
Whole & 36 & & & & 48.847 & 6.680 \\
Oral reading ability** & & & & & \\
Upper & 12 & 14.125 & .711 & & 59.100 & 3.700 \\
Lower & 8 & 9.125 & 1.382 & & 32.763 & 7.275 \\
Whole & 36 & 12.014 & 2.009 & & 48.000 & 10.600 \\
Amount of oral reading & practice & & & & \\
Upper & 7 & 291.714 & 100.023 & & 67.008 & 12.742 \\
Lower & 8 & 100.875 & $2.475^{7}$ & & 42.697 & $.315^{7}$ \\
Whole & 36 & 159.750 & 80.887 & & 50.197 & 10.304 \\
\hline
\end{tabular}

*English language ability as measured by $\mathrm{T}$-scores was adopted. ${ }^{* *} \mathrm{~T}$-scores of oral reading ability were calculated with the experimental and control groups $(n=73)$ in Miyasako (2002).

Table 2. Means of English Language Ability in Upper and Lower English-language-ability Groups

\begin{tabular}{llrll}
\hline Group & Test & $\mathrm{n}$ & Mean & SD \\
\hline Upper & pre & 8 & 57.725 & 2.745 \\
& post & 8 & 59.262 & 4.055 \\
Lower & pre & 14 & 42.121 & 2.940 \\
& post & 14 & 47.071 & 3.866 \\
\hline
\end{tabular}




\subsubsection{Oral Reading Ability}

Table 3 shows the means of English language ability for the upper and lower oral-reading-ability groups. The upper group decreased in the mean during the experiment (pre $=54.008$, post $=53.808$ ), but the lower group gained more than five points (pre $=42.575$, post $=48.237$ ). The 2 (oral reading ability) $\times 2$ (period) repeated-measures ANOVA revealed significant main effects of condition $[F(1,18)=12.980, p<.01]$ and period $[F(1,18)=10.088, p<.01]$. There was also a significant interaction between the two variables $[F(1,18)=11.620, p<.01]$. It seemed that the lower oral-reading-ability group improved their English language ability significantly more than the upper oral-readingability group during the experiment.

\subsubsection{Amount of Oral Reading Practice}

Table 4 shows the means of English language ability for the upper and lower oral-reading-practice groups. The upper group (pre $=49.757$, post $=55.429$ ) increased in the mean more than the lower group (pre $=46.775$, post $=47.800$ ) during the experiment. The 2 (oral reading practice) $\times 2$ (period) repeated-measures ANOVA showed significance in the main effect of period $[\mathrm{F}(1,13)=11.904, \mathrm{p}<.01]$ but no significance in the main effect of condition $[F(1,13)=2.809, n s]$. However, there was a significant interaction between the two variables $[F(1,13)=5.731, p<.05]$. It seemed that the upper oral-reading-practice group improved their English language ability significantly more than the lower oral-reading-practice group during the experiment.

Table 3. Means of English Language Ability in Upper and Lower Oral-reading-ability Groups

\begin{tabular}{llrll}
\hline Group & Test & $\mathrm{n}$ & Mean & SD \\
\hline Upper & pre & 12 & 54.008 & 4.197 \\
& post & 12 & 53.808 & 6.313 \\
Lower & pre & 8 & 42.575 & 5.896 \\
& post & 8 & 48.237 & 5.535 \\
\hline
\end{tabular}

Table 4. Means of English Language Ability in Upper and Lower Oral-reading-practice Groups

\begin{tabular}{lllll}
\hline Group & Test & $\mathrm{n}$ & Mean & SD \\
\hline Upper & pre & 7 & 49.757 & 8.415 \\
& post & 7 & 55.429 & 6.544 \\
Lower & pre & 8 & 46.775 & 5.095 \\
& post & 8 & 47.800 & 5.352 \\
\hline
\end{tabular}




\subsubsection{Relationships between Constructs}

In order to investigate the relationships between the participants' English language ability, oral reading ability, amount of oral reading practice and improvement of English language ability, which was computed as the post-minus-pre-test score (Mean $=2.067$, $\mathrm{SD}=4.631, \mathrm{n}=36$ ), Pearson product-moment correlation coefficients were calculated for the whole group (Table 5). The result showed that the participants' improvement of English language ability had significant negative correlations with their English language ability $(r=-.451, p<.01)$ and oral reading ability $(r=-.374, p<.05)$, but a significant positive correlation with their amount of oral reading practice $(r=.376, p<.05)$.

This result was confirmed by the stepwise regression analysis, showing that English language ability $(\beta=-.340, t=-3.556, p<.01)$ and the amount of oral reading practice $(\beta=.024$, $t=3.059, p<.01$ ) were significant predictors of the improvement of English language ability. English language ability and the amount of oral reading practice uniquely explained $20.3 \%$ and $14.1 \%$ of the variance of the improvement of English language ability respectively (Table 6). The reason that oral reading ability, significantly correlated with the improvement of English language ability, was not a significant predictor of the improvement of English language ability is considered to have lain in its multi-collineality with the English language ability $(r=.621, p<.01$; Table 5). It seems that students with lower English language ability and higher oral reading practice improved their English language ability during the experiment.

Table 5. Correlation Matrix between Constructs

\begin{tabular}{lllll}
\hline & $\mathrm{A}$ & $\mathrm{B}$ & $\mathrm{C}$ & $\mathrm{D}$ \\
\hline English language ability (A) & - & & & \\
Oral reading ability (B) & $.621^{* *}$ & - & & \\
Amount of oral reading practice (C) & .093 & -.261 & - & \\
Improvement of English language ability (D) & $-.451^{* *}$ & $-.374^{*}$ & $.376^{*}$ & - \\
\hline
\end{tabular}

${ }^{* *} \mathrm{p}<.01,{ }^{*} \mathrm{p}<.05 . \quad \mathrm{n}=36$.

Table 6. Regression Analysis for Improvement of English Language Ability

\begin{tabular}{lllll}
\hline & $\beta$ & $\mathrm{t}$-value & $\mathrm{p}$-value & $\mathrm{R}^{2}$ \\
\hline English language ability & -.340 & -3.556 & .001 & .203 \\
Amount of oral reading practice & .024 & 3.059 & .004 & .141 \\
\hline $\mathrm{Y}=14.800-.340 \mathrm{X}_{1}+.024 \mathrm{X}_{2} ; \mathrm{R}^{2}=.379 ; \mathrm{F}(2,33)=10.076, \mathrm{p}<.01, \mathrm{n}=36$. &
\end{tabular}


Table 7. Means of Metacognition of Oral Reading for Item 33 in Upper and Lower English-language-ability Groups

\begin{tabular}{|c|c|c|c|c|c|}
\hline Item & Test & & & & \\
\hline No. & & Mean & $\mathrm{SD}$ & Mean & SD \\
\hline 33 & pre & 3.375 & 1.061 & 2.000 & .679 \\
\hline & post & 3.125 & .991 & 2.929 & .917 \\
\hline
\end{tabular}

Numbers were 8 and 14 for the upper and lower groups respectively.

Table 8. Means of Metacognition of Oral Reading for Items 27, 32 and 33 in Upper and Lower Oral-reading-ability Groups

\begin{tabular}{|c|c|c|c|c|c|}
\hline \multirow{2}{*}{$\begin{array}{l}\text { Item } \\
\text { No. }\end{array}$} & \multirow[t]{2}{*}{ Test } & \multicolumn{2}{|c|}{ Upper } & \multicolumn{2}{|c|}{ Lower } \\
\hline & & Mean & SD & Mean & SD \\
\hline \multirow[t]{2}{*}{27} & pre & 3.250 & .452 & 2.125 & .354 \\
\hline & post & 2.833 & .835 & 2.500 & .756 \\
\hline \multirow[t]{2}{*}{32} & pre & 2.833 & .577 & 1.750 & .707 \\
\hline & post & 2.917 & .669 & 2.625 & .744 \\
\hline \multirow[t]{2}{*}{33} & pre & 3.000 & .953 & 2.250 & .707 \\
\hline & post & 3.083 & .900 & 3.000 & .535 \\
\hline
\end{tabular}

Numbers were 12 and 8 for the upper and lower groups respectively.

Table 9. Means of Metacognition of Oral Reading for Items 22 and 29 in Upper and Lower Oral-reading-practice Groups

\begin{tabular}{|c|c|c|c|c|c|}
\hline \multirow{2}{*}{$\begin{array}{l}\text { Item } \\
\text { No. }\end{array}$} & \multirow{2}{*}{ Test } & \multicolumn{2}{|c|}{ Upper } & \multicolumn{2}{|c|}{ Lower } \\
\hline & & Mean & $\mathrm{SD}$ & Mean & $\mathrm{SD}$ \\
\hline \multirow[t]{2}{*}{22} & pre & 3.143 & 1.464 & 2.875 & 1.126 \\
\hline & post & 4.000 & 1.000 & 2.250 & 1.282 \\
\hline \multirow[t]{2}{*}{29} & pre & 2.571 & .787 & 2.250 & .707 \\
\hline & post & 3.571 & 1.134 & 2.000 & .756 \\
\hline
\end{tabular}

Numbers were 7 and 8 for the upper and lower groups respectively.

\subsection{Effects on Metacognition of Oral Reading}

\subsubsection{English Language Ability}

In order to examine which of the upper and lower English-language-ability groups changed the metacognition of oral reading more significantly, independent 2 (English language ability) $\times 2$ (period) repeated-measures ANOVAs on the 4 factors and 51 items concerning the metacognition of oral reading were performed. The results showed that only item 33 showed a significant interaction between the condition and period $[\mathrm{F}(1$, $20)=16.780, p<.01$ ]. Table 7 shows that in this item, the lower group (pre $=2.000$, post $=2.929$ ) increased the mean of the metacognition of oral reading more than the upper 
group (pre=3.375, post=3.125). It seemed that the lower English-language-ability group improved the following metacognition of oral reading significantly more than the upper English-language-ability group: when you read a text aloud in English, "you can make fairly appropriate pauses".

\subsubsection{Oral Reading Ability}

Similarly, 2 (oral reading ability) $\times 2$ (period) repeated-measures ANOVAs were independently performed on the 4 factors and 51 items to compare the changes in the metacognition of oral reading between the upper and lower oral-reading-ability groups. The results showed significance in the interaction between the two variables in item $27[\mathrm{~F}(1$, $18)=5.018, \mathrm{p}<.05]$, item $32[\mathrm{~F}(1,18)=5.530, \mathrm{p}<.05]$ and item $33[\mathrm{~F}(1,18)=4.562, \mathrm{p}<.05]$. In these items, the lower group gained more points than the upper group in the mean of the metacognition of oral reading. The gains were .375 and -.417 in item $27, .875$ and .084 in item 32, and .750 and .083 in item 33 for the lower and upper groups respectively (Table 8). It seemed that the lower oral-reading-ability group improved the following metacognition of oral reading significantly more than the upper oral-reading-ability group during the experiment: when you read a text aloud in English, "you can understand the content of the text (item 27)", "you can use intonation fairly appropriately (item 32)" and "you can make fairly appropriate pauses (item 33 )".

\subsubsection{Amount of Oral Reading Practice}

According to the independent 2 (oral reading practice) $\times 2$ (period) repeated-measures ANOVAs on the 4 factors and 51 items, there were significant interaction effects between the two variables in item $22[\mathrm{~F}(1,13)=4.690, \mathrm{p}<.05]$ and item $29[\mathrm{~F}(1,13)=6.594, \mathrm{p}<.05]$. In these items, the upper group increased in the mean of the metacognition of oral reading (.857 and 1.000 in the gains for items 22 and 29 respectively), but the lower group decreased the figures ( -.625 and -.250 in the losses for items 22 and 29 respectively) (Table 9). It seemed that the upper oral-reading-practice group improved the following metacognition of oral reading significantly more than the lower oral-reading-practice group: when you read a text aloud in English, "you can remember the content of the text (item 22)" and "you can make appropriate sound-changes (item 29)".

\section{DISCUSSION}

\subsection{Research Questions (1) and (2)}

The first and second research questions were: (1) who improved English language ability more greatly, senior high school students with higher or lower English language ability?; and (2) did oral reading ability and the amount of oral reading practice for senior high school students affect the improvement of their English language ability?

The results showed: (a) students with lower English language ability improved their English language ability significantly more than students with higher English language 
ability; (b) students with lower oral reading ability improved their English language ability significantly more than students with higher oral reading ability; (c) students with higher amount of oral reading practice improved their English language ability significantly more than students with lower amount of oral reading practice; and (d) English language ability and the amount of oral reading practice could uniquely predict the improvement of English language ability for the students. In short, the oral reading practice was effective for students with lower English language ability, with lower oral reading ability and with higher amount of oral reading practice in improving their English language ability, and especially so for students with lower English ability and higher amount of oral reading practice.

These findings may be accounted for by the above-shown assumptions of oral reading in the improvement of learners' English language ability (Section 1): (a) exposure to English for lexical development; (b) opportunities to raise consciousness for grammar development; and (c) improvement in the phonological processing of written information.

First, students with lower English language ability must have expanded their vocabulary by reading the same passages aloud 8 to 24 times $^{8}$, which is more than a necessary amount of encounter for acquiring new lexical items, 5 to 16 times (Nation, 1990). Contrary to this, students with higher English language ability probably found far smaller numbers of unfamiliar lexical items in the materials which had been covered in class before.

Second, students with lower English language ability may have also developed their grammar more greatly than students with higher English language ability. While reading the same passages aloud repeatedly, the lower English-language-ability students may have noticed more gaps in grammatical constructions with their interlanguages and may have restructured them. In other words, the lower English-language-ability students may have had more to acquire about grammar from the same materials than the higher English-language-ability students.

Third, students with lower oral reading ability, who probably had not acquired a good letter-sound association before the experiment, must have improved the efficiencies of their phonological processing of words. Consequently, the improved decoding may have enabled the students to spare their working memory capacities for lexical processing and higher-level reading skills such as syntactic parsing and comprehension. In this case, the spared cognitive resources for these reading skills may have contributed to the improvement of their English language ability. Meanwhile, students with higher oral reading ability may have had less to attain in the decoding of information.

Finally, the improvement of English language ability for students with higher amount of oral reading practice may be taken for granted. It is natural that when students try to learn something, those who spend more time and energy on it can achieve better results. 


\subsection{Research Question (3)}

The third research question was: did English language ability, oral reading ability and the amount of oral reading practice for senior high school students affect the changes of their metacognition of oral reading? The results showed: (a) students with lower English language ability improved their metacognition of oral reading concerning making proper pauses significantly more than students with higher English language ability; (b) students with lower oral reading ability improved their metacognition of oral reading, which concerned comprehending a passage, using a proper intonation and making proper pauses, significantly more than students with higher oral reading ability; and (c) students with higher amount of oral reading practice improved their metacognition of oral reading, which concerned remembering the content of a passage and making proper sound changes, significantly more than students with lower amount of oral reading practice.

These findings are in line with those concerning English language ability. First, the greater improvement in the metacognition of proper pause making for students with lower English language ability may have been generated by their greater improvement of English language ability than that of students with higher English language ability. This is because pause making has relevance to lexical chunks and grammar that are important components of English language ability.

Second, the greater improvement in the metacognition for students with lower oral reading ability concerned better passage comprehension and more proper intonation use and pause making. These changes are also considered to have come from the improvement of their English language ability. One reason for this is, not mentioning reading comprehension, that intonation is a predictor of English language proficiency, measured as the scores of the past STEP third and pre-second grade exam., and is correlated with vocabulary, grammar and reading, which make components of proficiency (Miyasako, 2002). Another reason concerning pause making is the same as the above case of the lower English-language-ability students. Thus, the perception changes on these points seem to have reflected the improvement of their English language ability.

Finally, although students with higher amount of oral reading practice made favorable changes in the metacognition of proper sound changes they made and better content remembrance, in the former they may have just expressed a progress in their articulation of words. On the other hand, their perception change on content remembrance may have been indirectly related to the improvement of their English language ability. The reason for this is that the higher oral-reading-practice students may have improved their phonological processing of written information or the efficiency of phonological loop in working memory. Their improved phonological processing in turn may have led to better lexical processing and higher-level reading skills with more working memory capacities spared. In this case, their long-term memory may have also functioned more efficiently, which may have been perceived as better content remembrance. A better memory can make a part of higher English language ability. It seems that the improvement of English 
language ability for the higher oral-reading-practice students was reflected in their metacognition change of content remembrance.

\section{CONCLUSION AND IMPLICATIONS}

This re-examination study revealed the effectiveness of oral reading practice in the improvement of English language ability for students with lower English language ability, with lower oral reading ability and with higher amount of oral reading practice, especially so for students with lower English language ability and higher amount of oral reading practice, and this finding was reflected in their metacognition of oral reading.

Probable contributors to the results include: (a) the expansion of vocabulary for students with lower English language ability; (b) the enhancement of grammar development through consciousness raising for students with lower English language ability; (c) the improvement in the efficiency of phonological processing of words for students with lower oral reading ability; and (d) the function of causality for students with higher amount of oral reading practice.

These findings gave us implications to EFL pedagogy in Japan. First, we should appreciate the effectiveness of oral reading practice in developing English language ability for many junior and senior high school students. The reason for this lies in a fact that although the lower English-language-ability students in this study were first-year senior high school students with English language ability below 45 as measured by the T-score of Benesse-Shinken-moshi, which was developed mainly for academic senior high schools, most of the lower English-language-ability students supposedly belong to the upper half of the whole first-year senior high school population nationwide. Thus, the effectiveness of oral reading practice for the lower English-language-ability students should apply to other junior and senior high school students with similar or lower English language ability.

Second, we should assign oral reading to a more central and systematic role in our daily instruction of English. Since oral reading has often been neglected or given only a minor role in class, it may be caught in a vicious circle, consisting of sporadic use of oral reading practice in class, its ineffectiveness and teachers' perception of its ineffectiveness. It should not be disregarded that the improvement of English language ability for the lower-level students was achieved in the three-month experiment.

Third, we should pay more attention to learners' metacognition of oral reading. Since some of learners' metacognition of oral reading, such as pause making and intonation, changes in accordance with their improvement of English language ability, we may be able to roughly evaluate their improvement in English language ability from their metacognition change. Another possibility concerning the metacognition is its instruction aimed at the improvement of learners' English language ability. For example, the instruction of raising awareness on pause making might help to enhance learners' acquisition of grammar and lexical chunks. The metacognition of oral reading seems to have potential for contributing to the development of English language ability. 
Not only the implications but limitations of the study should be mentioned. First, the number of the participants was small. The sample size did not allow us to perform three-way repeated-measures ANOVAs, which were more preferable for the analyses of this study. Another weakness of the sample size concerns possible Type I errors, i.e., errors mistakenly revealing that a difference is significant, made in the analyses. Although significance at the level of .05 was adopted in this study, most of the possible Type I errors would have been evaded by the adoption of .01 level. However, this more stringent significance-level would have shown significant differences only in the improvement of English language ability between students with higher and lower oral reading ability, and in the improvement of the metacognition of oral reading between students with higher and lower English language ability. Thus, we may have to be cautious in accepting the findings of this study as they are.

Second, there were conditions unequal to some groups of students. Although the same oral reading material was used for all the participants, this treatment seems to have given students with lower English language ability and with lower oral reading ability advantages in the development of vocabulary and grammar. These students had more to learn about these components in the material than their counterparts. Also, students with higher amount of oral reading practice clearly spent more time reading aloud out of class than students with lower reading practice.

These shortcomings do not invalidate all the findings of this study, but we should confirm the findings in better-designed studies revising them: (a) by adopting a larger sample that can avoid Type I errors in the analyses; (b) by devising oral reading materials that can minimize inequality among the participants in the learning of vocabulary and grammar; and (c) by controlling the amount of oral reading practice. Moreover, future research on the improvement of English language ability by reading aloud should include investigating probable beneficiaries of oral reading practice, appropriate reading-aloud materials and motivating way of oral reading practice, reflecting learners' individual differences.

\section{NOTES}

1. English language ability makes part of English language proficiency, which usually includes global English language performance as well as its competence (McNamara, 1996). It is defined as learners' language ability, which is developed in the EFL instruction of Japan, mainly concerning reading, grammar and vocabulary of English. This is the kind of ability that is usually measured by entrance examinations for colleges and universities. One reason for our preference of this concept to English language proficiency lies in a fact that Japanese senior high school students hardly use English communicatively. This situation may take away the meaning of measuring their English language proficiency. 
2. Miyasako (2002) had no problem in the inter-rater consistency (pre: $r=.831$; post: $r=.701$, $\mathrm{n}=73$ ).

3. Bennese-Shinken-moshi is arguably a valid measure of English language ability for senior high school students. For example, T-scores of the non-mark type Shinken-moshi in October, 2002 for mainly third year students had a significant correlation with their self-marked scores of Standardized Preliminary Examinations for University, a supposedly valid measure of English language ability for university applicants ( $r=.726, p<.01, n=275)$. Thus, Shinken-moshi is considered to have validly gauged English language ability for the participants at the times of administration.

4. The participants recorded their reading-aloud journals from the onset to the end of winter vacation for about two and a half months.

5. Kirihara-shoten generously gave us a permission to use the sound source for this research.

6. This was adopted to make the data balanced. In the case of the lower oral-reading-practice group having the participants with their T-scores below 45, the numbers were 7 and 15 for the upper and lower oral-reading-practice groups respectively. In the adopted case of the lower oral-reading-practice group having those with their T-scores below 44, the numbers were 7 and 8 for the upper and lower oral-readingpractice groups respectively, which made a balanced data.

7. Most of the lower oral-reading-practice group did not practice oral reading out of class, meaning their amount of oral reading practice was 100 , the base line. Thus, the group's SD was distinctively small compared with the upper oral-reading-practice group.

8. According to Table 1, the means of the amount of oral reading practice in the lower and upper oral-reading-practice groups were 100.875 and 291.714. Since the reading-aloud material was composed of 12 sections, the means of amount in reading aloud the whole passages for the lower and upper oral-reading-practice groups were 8.406 and 24.310.

\section{REFERENCES}

Anderson, J. R. (1995). Learning and Memory: An Integrated Approach (2nd edition). New York: John Wiley \& Songs, Inc.

Baddeley, A. D. (1992). Working memory. Science, 255, 556-559.

Baddeley, A. D. (1997). Human Memory: Theory and Practice (revised edition). Hove: Psychology Press.

Baddeley, A. D. (1999). Essentials of Human Memory. Hove: Psychology Press.

Baddeley, A. D., Gathercole, S. E., \& Papagno, C. (1998). The phonological loop as a language learning device. Psychological Review, 105, 158-173.

Carrell, P. L. (1989). Metacognitive awareness and second language reading. Modern Language Learning, 73, 121-134.

Ellis, R. (1997). SLA Research and Language Teaching. Oxford: Oxford University Press. 
Gathercole, S. E., \& Baddeley, A. D. (1993). Working Memory and Language. Hove: Psychology Press.

Kadota, S. (2002). Eigo no Kakikotoba to Hanashikotoba wa Ikani Kankei Shiteiruka [How Phonology Works in L2 Reading Comprehension]. Tokyo: Kuroshio Shuppan.

Kido, H. (1993). Reading Aloud no koka wo shidojikken niyotte kenshosuru [An experimental study on the effect of reading-aloud teaching]. Eigokyoiku Kenkyu [Studies on English Language Education], 16, 136-143.

Kunihiro, M. (1999). Kunihiroryu Eigo no Hanashikata [How to Speak English in the Manner of Kunihiro]. Tokyo: Tachibana Shuppan.

Kunihiro, M. (Ed.). (2000). Eikaiwa Zettai Ondoku [Improving English Conversation by Oral Reading]. Tokyo: Kodansha International.

McNamara, T. (1996). Measuring Second Language Performance. New York: Longman.

Miyasako, N. (2002). Kokosei no ondoku to eigoryoku wa kankei ga aruka [What relationships does oral reading have with English ability?]. STEP Bulletin, 14, 14-25.

Miyasako, N. (2003). Shadoingu, ondoku, patan purakutisu ni yoru chokai, dokkairyoku kojo ni kansuru ninchi purosesu kara no ichi kosatsu [A study on shadowing, oral reading and pattern practice from a viewpoint of cognitive processing]. YASSELE, 7, 21-28.

Miyasako, N., \& Takatsuka, S. (in press). What relationships do the efficiencies of phonological coding and lexical access have with reading comprehension for Japanese learners of English? ARELE. Vol. 15.

Nation, I. S. P. (1990). Teaching \& Learning Vocabulary. Boston: Heinle \& Heinle Publishers.

Schmidt, R. (2001). Attention. In Robinson, P. (Ed.), Cognition and Second Language Instruction, 3-32. Cambridge: Cambridge University Press.

Shiozawa, T. (Ed.). (1998). Spectrum English Course I. Tokyo: Kirihara shoten.

Skehan, P. (1998). A Cognitive Approach to Language Learning. Oxford: Oxford University Press.

Suzuki, J. (1998). Onsei kyozai no pozu ga ridingu supido ni oyobosu eikyo ni kansuru jissho teki kenkyu [An empirical study on the effect of pauses in listening materials on reading speed]. In Kotoba no kagaku kenkyukai (Ed.), Kotobano Shinri to Gakushu [Verbal Psychology and Learning], 311-326. Tokyo: Kinseido.

Takanashi, Y., \& Takahashi, M. (1987). Eigo Ridingu Shido no Kiso [Foundations of English Reading Pedagogy]. Tokyo: Kenkyusya shuppan.

Takayama, Y. (1995). Ridingu no gakushu to shido [Teaching and learning of reading in English]. In Kanatani, K. (Ed.), Eigo Ridingu Ron [Reading in English] , 76-119. Tokyo: Togensha.

Tamai, K. (2001). Lisuningu shidoho toshiteno shadoingu no koka ni kansuru kenkyu [A study on the effect of shadowing in EFL listening pedagogy]. Unpublished doctoral dissertation submitted to Kobe University. 
Watanabe, Y. (1990). Ondoku saiko: Mokudoku no sokudoku-ka wo unagasu ondoku sido no igi to arikata [Reconsideration of oral reading: why and how oral reading improves silent reading speed]. Leo, 19, 101-30.

Williams, M., \& Burden, R. L. (1997). Psychology for Language Teachers: A Social Constructivist Approach. Cambridge: Cambridge University Press.

\section{APPENDIX 1. Four Criteria in the Evaluation of ORA}

\section{Pronunciation (5-point-scale)}

5: The examinee can convey the message accurately without any problems in pronunciation or in accentuation. 4: The examinee can convey the message satisfactorily with a few problems in pronunciation or in accentuation. 3: The examinee can barely convey the message with some problems in pronunciation or in accentuation. 2: The examinee has some trouble in conveying the message with rather many problems in pronunciation or in accentuation. 1: The examinee has much trouble in conveying the message with many problems in pronunciation or in accentuation.

Intonation (5-point-scale)

5: The examinee can convey the message accurately without any problems in intonation.

4: The examinee can convey the message satisfactorily with a few problems in intonation. 3: The examinee can barely convey the message with some problems in intonation. 2: The examinee has some trouble in conveying the message with rather many problems in intonation. 1: The examinee has much trouble in conveying the message with many problems in intonation.

Pause making (5-point-scale)

5: The examinee can convey the message accurately without any problems in making pauses. 4: The examinee can convey the message satisfactorily with a few problems in making pauses. 3: The examinee can barely convey the message with some problems in making pauses. 2: The examinee has some trouble in conveying the message with rather many problems in making pauses. 1: The examinee has much trouble in conveying the message with many problems in making pauses.

\section{Delivery (5-point-scale)}

5: The examinee can convey the message accurately without any problems in delivery. 4 : The examinee can convey the message satisfactorily with a few problems in delivery. 3 : The examinee can barely convey the message with some problems in delivery. 2: The examinee has some trouble in conveying the message with rather many problems in delivery. 1: The examinee has much trouble in conveying the message with many problems in delivery.

\section{APPENDIX 2. Questionnaire on Oral Reading}

This 5-point Likert-scale questionnaire, consisted of 4 factors and 51 items, was conducted in Japanese: $5=$ strongly agree, $1=$ strongly disagree. 


\section{Factor I: perceptions on what you can do or strategies you can use in reading aloud} Concerning reading aloud: (11) you read aloud paying attention to pronunciation; (12) you read aloud paying attention to intonation; (13) you read aloud paying attention to making proper pauses; (14) you read aloud paying attention to delivering the proper message.

When you read a text aloud in English: (15) you can anticipate what comes next in the text; (16) you can recognize the difference between main points and supporting details; (17) you can relate information which comes next in the text to previous information in the text; (18) you can question the significance or truthfulness of what the author says; (19) you can use your prior knowledge and experience to understand the content of the text; (21) you can guess the content of the text; (22) you can remember the content of the text; (26) you can move your mouth automatically; (27) you can understand the content of the text; (28) you can distinguish important words from unimportant ones; (29) you can make appropriate sound-changes; (30) you can read the text aloud fairly rapidly; (31) you can pronounce fairly appropriately; (32) you can use intonation fairly appropriately; (33) you can make fairly appropriate pauses; (34) you can convey the content of the text fairly appropriately; (35) you can look ahead of what you are reading aloud; (36) you can understand the text in the word order of reading aloud; (37) you can know the relative importance of words.

\section{Factor II: perceptions on effective strategies in reading aloud}

A good oral reader in English: (72) is good at recognizing words; (73) is good at pronunciation; (74) is good at understanding the overall meaning of the text; (76) is good at guessing the meanings of unknown words; (77) is good at integrating the information in the text with what she already knows; (78) is good at focusing on the details of the content; (80) is good at using appropriate intonation; (81) is good at making appropriate pauses; (82) is good at articulation; (83) is good at being expressive; (84) is good at pronunciation and accentuation; (85) is good at guessing the pronunciation and accentuation of unknown words.

Factor III: perceptions on what makes your oral reading difficult or what requires your attention to improve your oral reading

One thing that you do to read aloud effectively is to focus on: (49) the grammatical structures; (53) the organization of the text; (59) expressing the content appropriately.

One thing that makes your oral reading in English difficult is: (64) the grammatical constructions; (66) relating the text to what you already know about the text; (67) getting the overall meaning of the text; (68) the organization of the text; (69) intonation; (70) making appropriate pauses.

\section{Factor IV: perceptions on performing reading aloud}

Concerning oral reading in English: (1) you read aloud everyday; (4) you read texts in the course book aloud many times; (5) you study English by reading aloud English sentences as often as possible; (6) you read aloud when you prepare for English classes; (7) you read aloud when you review English classes; (8) you read aloud using the model reading in tapes or CDs; (9) you read the text aloud trying to understand its content. 